КУТОВАЯ Ксения Романовна,

магистрант Восточного института - Школы региональных и международных исследований ДВФУ

(г. Владивосток).

E-mail: kutovaia.kr@students.dvfu.ru

\title{
Рынок недвижимости Республики Корея: проблема высоких цен на жильё и меры государственного регулирования
}

\author{
удК 332 \\ DOI https://doi.org/10.24866/2542-1611/2021-1/75-81
}

Проблема чрезмерно высокой стоимости недвижимости уже на протяжении долгого периода времени является насущной как для правительства Республики Корея, так и для обычных граждан. В данной статье рассмотрены причины роста цен на жильё, текущая ситуация на рынке недвижимости в Республике Корея, меры государственного регулирования, а также основные тенденции рынка. Автор обращает внимание на политику администрации действующего президента Республики Корея Мун Чжэина в отношении рынка недвижимости.

\section{Республика Корея - одна из стран с самыми высокими ценами на недвижимость}

На протяжении уже не одного десятилетия цены на недвижимость в Республике Корея (далее - РК) остаются на критично высоком уровне. Причин этому несколько. Во-первых, площадь РК составляет всего 100,210 км², что вынуждает корейцев при строительстве новых сооружений эффективно и экономично использовать каждый квадратный метр, что соответственно повышает стоимость как земельных участков, так и недвижимости.

Во-вторых, в этом вопросе присутствует и исторический фактор. С момента формирования жилищного рынка в 19601970-х гг. недвижимость являлась самым прибыльным и безопасным инвестиционным инструментом в РК. Это актив, который меньше всего облагался налогом и с большей вероятностью имел шансы вырасти в цене. Однако вскоре после Азиатского финансового кризиса 1997-1998 гг. цены на жильё упали на 45\%. Богатые граждане, не теряя времени, воспользовались шансом и вложили активы в недвижимость. В то же время правительство ослабило контроль над рынком, а различные финансовые учреждения диверсифицировали кредитование, облегчив условия ипотечного кредитования для физических лиц. С одной стороны, такой шаг со стороны банков позволил многим корейским семьям приобрести собственные дома и квартиры, но, с другой стороны, это открыло дверь для распространения спекуляций, ставших ещё одной проблемой южнокорейского рынка недвижимости [11, с. 1074].

Согласно статистике, приведенной в марте 2020 года американской консалтинговой компанией Mercer, Сеул, столица страны, располагается на 11-м месте среди 209 городов с наиболее высокой стоимостью жилой недвижимости в мире [6]. Средний ценовой диапазон на жильё в главном городе РК до-

рынок недвижимости, повышение иен, государственные мерь, жильё

Для иитирования:

Кутовая К. Р. Рынок недвижимости Республики Корея: проблема высоких цен на жильё и меры государственного регулирования // Известия Восточного института. 2021. № 1. C. 75-81. DOI

https://doi.org/10.24866/25421611/2021-1/75-81 
стиг 950 млн вон в феврале 2020 года, что, по мнению корейских экспертов, являлось самым высоким показателем за всю историю страны. Помимо этого, только за последние три года средняя стоимость апартаментов выросла с 7,95 млн вон за 1 кв. м до 12,59 млн вон [8].

Постоянное повышение цен на рынке недвижимости привело к тому, что более половины квартир в Сеуле классифицируются как «дорогие», на которые налагаются ограничения в отношении предоставления жилищных ссуд, так как пороговое значение составляет 900 млн вон. В 11 районах столицы к югу от реки Ханган средняя стоимость квартир доходит до отметки в 1,2 млрд вон, в то время как в 14 районах к северу от реки - 671 млн вон. Приведенные статистические данные позволяют выделить наиболее востребованные части города для приобретения недвижимости. К причинам более низких цен на северной стороне относят меньшие кредитные ограничения для покупателей.

В настоящее время среднестатистическому корейцу требуется на протяжении более чем 14 лет копить на приобретение собственной квартиры, при этом не тратя ни копейки [5]. Поэтому гражданам РК всё чаще приходится прибегать к различным уловкам, способствующим ускорению процесса покупки недвижимости. Одной из таких мер является увольнение одного из супругов с места работы с целью официального понижения дохода семьи, которое в свою очередь даст паре шанс получить государственное жильё по низким ценам. Зная уже только этот пример, можно прочувствовать глубину жилищной проблемы южнокорейского общества.

Государственная политика в отношении рынка недвижимости при администрации Мун Чжэина

В своей предвыборной кампании президент Республики Корея Мун Чжэин пообещал уделить особое внимание проблемам рынка недвижимости, в особенности в жилищном секторе. И он активно выполняет обещанное.

В 2018 г. администрация Мун Чжэина объявила о новом повышении комплексной ставки налога на недвижимость для владельцев дорогих резиденций и тех, в чьём владении более 1 жилищной единицы, с целью обуздать стремительно растущие цены на жильё. Комплексный налог на недвижимость является государственным налогом, взимаемым с владельцев нескольких объектов недвижимости или недвижимости премиум-класса. Получил негласное название «налог для богатых». Он отделен от налога на имущество, который взимается местными органами власти.

Согласно этой государственной мере, доход граждан, обладающих несколькими объектами недвижимости, располагающимися в зонах с наиболее высокой стоимостью квартир, будет облагаться налогом до $3,2 \%$ [7]. Эта мера была введена в качестве дополнения к налоговой реформе, проведённой в июле 2018 г., когда произошло увеличение налога до 2,5\%. По словам представителя Министерства планирования и финансов, данный шаг должен был позволить рационализировать стоимость владения недвижимостью в долгосрочной перспективе, вынуждая общественность делать более разумные инвестиции, что в итоге приведет к устойчивому развитию рынка.

Однако повышение налогов не помогло в полной мере решить проблему роста цен в РК. Как отметил профессор университета Мёнчжи 
Квон Дэчжун, политика ужесточения регулирования рынка прошла успешно только наполовину [3]. Он высказал мнение, что произошло изменение тенденций на рынке недвижимости вследствие установления более высокого комплексного налога, но, несмотря на это, государственное регулирование подтолкнуло стоимость жилья в Сеуле к увеличению, одновременно снизив цены в других регионах страны. Что означает усиление поляризации между столицей и остальными городами Республики Корея. Наглядным примером является рост цен на $20 \%$ на квартиры в Сеуле, в то время как в других регионах он наблюдался только на $5 \%$.

С целью «охлаждения» рынка администрация президента приняла решение расширить зоны мониторинга районов с наиболее высоким уровнем спекуляций, в особенности к западу от Сеула. Помимо этого, города, прилегающие к столице страны, в числе которых Инчхон, Ансан, Осан и Пёнтхэк были внесены в правительственный список «целевых областей для модификации», где рост цен на жильё считается удвоенным. Ключевые города, такие как Тэчжон и Чхончжу, также были добавлены в список. Всего было перечислено 69 районов, что на 25 больше по сравнению с предыдущим разом [10].

В обозначенных выше областях для квартир стоимостью менее 900 млн вон будет принято соотношение кредитов к стоимости в размере $50 \%$, а для тех, которые стоят дороже - 30\%. Соотношение долга к доходу будет ограничено 50\%. Некоторым владельцам придётся платить более высокие налоги на прирост капитала [4].

Правительство Республики Корея внесло изменения в условия предоставления жилищных кредитов. Банкам будет запрещено выдавать кредиты предприятиям, ведущим бизнес в сфере аренды недвижимости, а тем, кто стремится занять деньги для жилищно-инвестиционных целей в подконтрольных районах, потребуется переехать в приобретенную недвижимость в течение 6 месяцев. Кроме того,

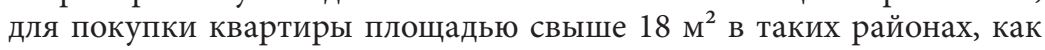
Самсон, Чхондам и Чамсил, потенциальные покупатели обязаны получить разрешение соответствующих местных органов. Покупателям необходимо дать согласие жить в новоприобретённой квартире не менее 2 лет, а также им запрещается её продавать или сдавать в аренду в течение данного срока. Цель этих мер заключается в попытке остановить безудержную практику спекулятивных покупок.

Что касается процентных ставок, то в РК они довольно низкие. Средняя процентная ставка по кредитам на жильё составила приблизительно 3,19\%. Исторически южнокорейский рынок недвижимости был достаточно чувствителен к изменениям процентных ставок, так как обычно 80-90\% жилищных кредитов имели плавающую ставку. Правительство Республики Корея продвигает политику кредитования с фиксированной ставкой для снижения рисков дефолта. Как отметил министр финансов Хон Намги в недавнем заявлении по поводу борьбы с последствиями коронавирусной инфекции: «...власти Южной Кореи более чем когда-либо решительно настроены стабилизировать рынок недвижимости, поскольку расходы на жильё напрямую связаны с уровнем жизни и благосостояния граждан» [9].

В августе 2020 года правительство Республики Корея опубликовало обновлённый перечь государственных мер, направленных на стабилизацию рынка. Во-первых, были повышены следующие нало- 


\begin{tabular}{|l|c|c|}
\hline & Август 2017 & Июль 2018 \\
\hline Сеул & 582,82 & $695,93(20 \%)$ \\
\hline Сеульская агломерация & 388,09 & $443,48(14 \%)$ \\
\hline Другие регионы & 192,50 & $192,50(5 \%)$ \\
\hline
\end{tabular}

Табл. 1. Средние цены на квартиры по регионам (млн вон).

Источник: [3]. ги: налог на имущество для владельцев нескольких единиц жилья, о котором уже упоминалось ранее, был увеличен с 3,2\% до 6\%, прибыль от недвижимости, получаемая корейскими корпорациями, будет облагаться налогом на дополнительные $20 \%$, а что касается налога на дарение недвижимого имущества, то его верхние пределы повысят с $62 \%$ до $72 \%$.

Во-вторых, были внесены изменения в законодательство, касающиеся корейской системы аренды чонсе, суть которой заключается в единовременной оплате аренды (около 70-80\%), вносимой на банковский счёт арендодателя в течение срока действия договора. У арендаторов появилась возможность автоматически продлевать договор аренды, что предоставляет им дополнительную защиту. Таким образом, арендодатель обязан регистрировать договор в правительственном учреждении и может прекратить его действие только в предписанных законом случаях. Также, повышение арендной платы при продлении периода съёма недвижимости не должно превышать 5\%. Следует отметить, что до принятия этого положения, частой практикой среди корейских арендодателей являлось постоянное увеличение стоимости аренды. В отдельных случаях домовладельцы могли увеличить ставку на 40-50\% в течение пятилетнего срока сдачи жилья [8].

Администрация Мун Чжэина и Демократическая партия «Тобуро» также занимаются вопросом спроса и предложения на рынке недвижимости в долгосрочной перспективе. Этим летом Министерство экономики и финансов Республики Корея объявило о плане строительства 260 тыс. домов в Сеуле и его окрестностях, часть из которых планируется как субсидированное жильё для молодых супружеских пар и тех, в чьей собственности пока нет ни одной единицы недвижимости. Согласно плану, ограничение по максимально разрешенной высоте кондоминиумов будет повышено с 35 этажей до 50 для более эффективного размещения населения. Также, на правительственных заседаниях неоднократно поднимался вопрос о переносе столицы из Сеула в Сечжон, что помогло бы снизить нагрузку на первый город. Однако данная идея всё ещё находится на стадии обсуждений, так как может привести к недовольству многих граждан.

Стоит отметить еще один фактор, который затормаживает снижение цен на рынке. Это нежелание некоторых социальных групп способствовать разрешению проблемы недвижимости. В первую очередь речь идёт о самих представителях власти. В августе 2020 г. несколько высокопоставленных чиновников, приближенных к президенту, подали в отставку по причине несогласия с указом Мун Чжэина о продаже дополнительной недвижимости. Документ относился к тем политическим деятелям, в чьей собственности находится более 1 единицы недвижимости. Данная меры была направлена на увеличение предло- 
жения в Сеуле и демонстрирования солидарности с общественностью [2].

Помимо определённых политиков, снижение стоимости жилья также невыгодно для тех семей, которые на протяжении многих десятилетий рассматривают недвижимость в качестве главного способа инвестирования либо для тех, кто ведёт бизнес, связанный с предоставлением аренды. Консерваторы РК всегда являлись надёжными защитниками интересов домовладельцев. Именно поэтому они пришли к решению бойкотировать парламентское голосование за пересмотр законов в отношении владения недвижимостью, оставив только демократов в Национальном собрании принимать поправки.

\section{Выводы}

Проблема чрезвычайно высокой стоимости недвижимости, особенно в жилом секторе, не нова для южнокорейского общества. В современных реалиях, когда цены растут практически каждый месяц, она ощущается особенно остро. Приобретение собственного жилья без кредитов и помощи семьи рассматривается среднестатистическим гражданином Республики Корея как невыполнимая задача.

Стоит заметить, что, говоря о высоких жилищных ценах, в первую очередь подразумевают столицу страны Сеул. Поляризация цен между главным городом РК и остальными населенными пунктами настолько велика, что ценовая разница составляет более 50\%. Возможно, идея правительства о перенесении столицы могла бы помочь снижению стоимости квартир и уменьшению поляризации, однако готовность корейских граждан к принятию данного решения остаётся под вопросом.

Действующий президент Мун Чжэин не первый государственный деятель, обративший внимание на данную проблему и предпринявший попытки её решения, однако он один из немногих, кто проводит настолько активную жилищную политику. И хотя пока его деятельность не принесла ощутимых результатов, а многие корейцы даже винят его в постоянном повышении цен на жильё, стоит учитывать тот факт, что и стоимость домохозяйств росла не один год. Автор считает, что для объективной оценки результативности и эффективности государственных мер администрации Мун Чжэина, необходимо дать новым законам и постановлениям время на полную имплементацию.

\section{Литература}

1. Bae Hyunjung. Finance minister warns against housing prices amid COVID-19 countermeasures // The Korea Herald (сайт) URL: http://www.koreaherald.com/view. php?ud=20200611000833 (дата посещения: 13.12.2020).

2. Borowiec Steven. Moon's support rate plummets as house prices keep soaring // Niikei Asia (сайт) URL: https://asia. nikkei.com/Politics/Moon-s-support-rate- plummets-as-house-prices-keep-soaring2 (дата посещения: 11.12.2020).

3. Choi Hyung-Jo. Real estate reform deepens polarization // Korea JoongAng Daily (сайт) URL: https://koreajoongangdaily.joins. $\mathrm{com} /$ news/article/article. aspx?aid=3051504 (дата посещения: 06.12.2020).

4. Jung Min-kyung. S. Korea rolls out stricter regulations to cool heated housing market // The Korea Herald (сайт) 
URL: http://www.koreaherald.com/view. php?ud=20200617000924 (дата посещения: 10.12.2020).

5. Kim C. Lost Seoul: South Korean middle-class dreams spoiled by soaring house prices // Reuters (сайт) URL: https://www. reuters.com/article/us-southkorea-economymiddleclass-insigh-idUSKCN2520K8 (дата посещения: 12.12.2020).

6. Lee Hyo-jin, Park Si-soo. Seoul 11th most expensive city for expats: survey // The Korea Times (сайт) URL: https://www.koreatimes.co.kr/www/ nation/2020/06/177_291126.html (Дата посещения: 10.12.2020).

7. Park S. Nathan. Moon Faces a Bigger Political Threat Than Kim Jong Un: Real Estate Prices // Foreign Policy (сайт) URL: https://foreignpolicy.com/2020/08/28/southkorea-jeonse-real-estate-economy-seoulmoon/ (дата посещения: 10.12.2020).

8. Seoul Apartment Prices Keep Soaring out of Reach // Chosun Media The Chosunilbo (сайт) URL: http://english.chosun.com/site/ data/html_dir/2020/02/27/2020022701969.

html (дата посещения: 08.12.2020).

9. S. Korea says will increase public housing to calm fears about home shortgages // Reuters (сайт) URL: https://www.reuters. com/article/southkorea-economy-housing/skorea-says-will-increase-public-housingto-calm-fears-about-home-shortgagesidUKS6N2DN00Z (дата посещения: 09.02.2021).

10. Lee Hyo-jin, Park Si-soo. Seoul 11th most expensive city for expats: survey // The Korea Times (сайт) URL: https://www.koreatimes.co.kr/www/ nation/2020/06/177_291126.html (дата посещения: 10.12.2020).

11. 김진수. 90년대 이후 주요不 動産 정책과 實效性 / 진수김 // 한국산학기 술학회논문지. 2013. 제 14권. 1073-1080 쪽. = Ким Джинсу. Правительственная политика и ее эффективность после 90-х гг. // Журнал Корейской Академии наук и технологий. 2013. № 14. С. 1073-1080.

Kseniia R. KUTOVAIA,

Graduate Student, Department of Oriental and African Studies, Oriental Institute - School of Regional and International Studies, FEFU (Vladivostok, Russia).

E-mail: kutovaia.kr@students.dvfu.ru

\section{Real Estate Market of the Republic of Korea: the Problem of High Housing Prices and Governmental Measures}

UDC 332

DOI https://doi.org/10.24866/2542-1611/2021-1/75-81

real estate market, price increase, governmental measures, housing
The problem of excessively high property values has been a pressing problem for both the government of the Republic of Korea and ordinary citizens for a long time. Today, this question has become a critical problem, since prices on the market are rising monthly, the attempts of the Government of the country to change the situation have not yet led to meaningful outcome, and the pressure on the society continues to grow. This article examines the reasons for the rise in housing prices, the current situation in the real estate market in the Republic of Korea, government regulation measures, and the main market trends. The author draws attention to the policy of the administration of the incumbent President of the Republic of Korea Moon Jaein regarding to the real estate market. The study advances our understanding of the problems of the real estate market in the Republic of Korea and its current status. 
For citation: Kutovaia K. R. Real estate market of the Republic of Korea: the problem of high housing prices and governmental measures // Oriental Institute Journal. 2021. № 1. P. 75-81. DOI https://doi. org/10.24866/2542-1611/2021-1/75-81

\section{References}

1. Bae Hyunjung. Finance minister warns against housing prices amid COVID-19 countermeasures // The Korea Herald (сайт) URL: http://www.koreaherald. com/view.php?ud=20200611000833 (data poseshheniya:13.12.2020).

2. Borowiec Steven. Moon's support rate plummets as house prices keep soaring // Niikei Asia (сайт) URL: https://asia. nikkei.com/Politics/Moon-s-support-rateplummets-as-house-prices-keep-soaring2 (data poseshheniya:11.12.2020).

3. Choi Hyung-Jo. Real estate reform deepens polarization // Korea JoongAng Daily (сайт) URL: https://koreajoongangdaily.joins. com/news/article/article.aspx?aid=3051504 (data poseshheniya:06.12.2020).

4. Jung Min-kyung. S. Korea rolls out stricter regulations to cool heated housing market // The Korea Herald (сайт) URL: http://www.koreaherald. com/view.php?ud=20200617000924 (data poseshheniya:10.12.2020).

5. Kim C. Lost Seoul: South Korean middle-class dreams spoiled by soaring house prices // Reuters (сайт) URL: https://www. reuters.com/article/us-southkorea-economymiddleclass-insigh-idUSKCN2520K8 (data poseshheniya:12.12.2020).

6. Lee Hyo-jin, Park Si-soo. Seoul 11th most expensive city for expats: survey // The Korea Times (сайт) URL: https://www.koreatimes.co.kr/www/ nation/2020/06/177_291126.html (Data poseshheniya:10.12.2020).

7. Park S. Nathan. Moon Faces a Bigger
Political Threat Than Kim Jong Un: Real Estate Prices // Foreign Policy (сайт) URL: https://foreignpolicy.com/2020/08/28/southkorea-jeonse-real-estate-economy-seoulmoon/ (data poseshheniya:10.12.2020).

8. Seoul Apartment Prices Keep Soaring out of Reach // Chosun Media The Chosunilbo (сайт) URL: http://english.chosun.com/site/ data/html_dir/2020/02/27/2020022701969. html (data poseshheniya:08.12.2020).

9. S. Korea says will increase public housing to calm fears about home shortgages // Reuters (сайт) URL: https://www. reuters.com/article/southkorea-economyhousing/s-korea-says-will-increasepublic-housing-to-calm-fears-abouthome-shortgages-idUKS6N2DN00Z (data poseshheniya:09.02.2021).

10. Lee Hyo-jin, Park Si-soo. Seoul 11th most expensive city for expats: survey // The Korea Times (сайт) URL: https://www.koreatimes.co.kr/www/ nation/2020/06/177_291126.html (data poseshheniya:10.12.2020).

11. 김진수. 90년대 이후 주요不 動産 정책과 實效性 / 진수김 // 한국산학기 술학회논문지. 2013. 제 14권. 1073-1080 쪽. = Kim Dzhinsu. Pravitel'stvennaya politika i ee ehffektivnost' posle 90-kh gg. // ZHurnal Korejskoj Akademii nauk i tekhnologij. 2013. № 14. C. 1073-1080. 